\title{
Pengembangan Media Pembelajaran Bahasa Indonesia Berbasis Website
}

\author{
Fajar Sukma Pratama \\ Universitas Indraprasta PGRI \\ Jalan Nangka No. 58 C/TB. Simatupang, Tanjung Barat, Jakarta Selatan 12530
}

fspratama@yahoo.com

\begin{abstract}
The purpose of this research is to 1) Create teaching media as a solution for Distance Learning in the pandemic; 2) Learning facilities to increase learning motivation especially high school students grade X. The research methodology used to create indonesian language learning media based on this website is a qualitative descriptive method using the approach of Model FOUR D and ADDIE Model with the results of this research concluded this research has produced a prototype product of Indonesian language learning media Class X semester 1 high school level through stages that adapt the ADDIE model (Branch, 2009). The selection of the model is due to the sekuensial and systematic ADDIE model to produce a learning media product. Indonesian learning media Grade $X$ semester 1 high school Wordpress platform and supported by other applications such as Ms. Office, Adobe photoshop, Google aplication, and Youtube. The learning media developed contains observation report text material, exostrosy, anecdotes, and folklore. The learning media that is created refers to the syllabus and RPP that have been created based on observations and references of previous face-to-face learning that meet the elements of KI and KD, Materials, Evaluation, Libraries, Instructions, and Profiles.
\end{abstract}

Keywords: learning media, websites, text reports, anecdotes, expositions.

\begin{abstract}
Abstrak
Tujuan Penelitian ini adalah untuk 1) Membuat media ajar sebagai solusi Pembelajaran Jarak Jauh di masa pandemi; 2) Sarana belajar agar meningkatkan motivasi belajar khusunya siswa SMA kelas $\mathrm{X}$. Metodologi penelitian yang digunakan untuk membuat media pembelajaran Bahasa Indonesia berbasis website ini adalah metode deskriptif kualitatif dengan menggunakan pendekatan Model FOUR D dan Model ADDIE dengan Hasil penelitian disimpulkan Penelitian ini telah menghasilkan sebuah produk purwarupa (prototype) media pembelajaran Bahasa Indonesia Kelas X semester 1 jenjang SMA melalui tahapan yang mengadaptasi model ADDIE (Branch, 2009). Pemilihan model tersebut dikarenakan model ADDIE sekuensial dan sistematis untuk menghasilkan sebuah produk media pembelajaran. Media pembelajaran Bahasa Indonesia Kelas X semester 1 jenjang SMA paltform Wordpress dan didukung aplikasi lainnya seperti Ms. Office, Adobe photoshop, Google aplication dan Youtube. Media pembelajaran yang dikembangkan memuat materi Teks Laporan Observasi, Eksosisi, Anekdot, dan Cerita Rakyat. Media pembelajaran yang dibuat mengacu pada silabus dan RPP yang sudah dibuat berdasarkan observasi dan rujukan pembelajaran tatap muka terdahulu yang memenuhi unsur KI dan KD, Materi, Evaluasi, Pustaka, Petunjuk, dan Profil.
\end{abstract}

Kata Kunci: media pembelajaran, website, teks laporan, anekdot, eksposisim.

\section{PENDAHULUAN}

Kondisi Pandemi COVID-19 tidak memungkinkan kegiatan belajar mengajar berlangsung secara normal, namun keputusan ini diambil demi mencegah serta memutuskan rantai penebaran Covid-19. Pemberlakuan program Belajar Dari 
Rumah (BDR) sebagai pola kegiatan belajar mengajar yang baru, sangan rentan denga kendala serta tantangan baru mengingat masa transisi ini berlangsung sangat cepat.

Pembelajaran Jarak Jauh tentunya berlaku bagi seluruh mata pelajaran. Dimana setiap mata pelajaran mempunyai karakteristik yang berbeda-beda dan kendala dalam menyampaikan materi ajar pun pastinya memiliki kesulitan tersendiri. Beberapa kendala yang timbul dalam pelaksanaan Pembelajaran Jarak Jauh (PJJ) diantaranya kesulitan guru dalam mengelola PJJ dan masih terfokus dalam penuntasan kurikulum. Sementara itu, tidak semua orang tua mampu mendampingi anak-anak belajar di rumah dengan optimal karena harus bekerja ataupun kemampuan sebagai pendamping belajar anak, serta sarana penunjang PJJ seperti, media bertemunya guru dan murid, video converence, pengelola file digital serta dukungan konektivitas akses internet (Rusman, 2017).

Menjaga keefisiensian serta keefektifan dalam proses belajar mengajar jarak jauh, penggunaan media teknologi informasi sangat dibutuhkan. Terlebih penggunaan media teknologi informasi yang terhubung menggunakan fasilitas internet baik itu berbasis aplikasi website, media sosial, android atau media pendukung lainnya (Rusman, 2012). Seperti diketahui bahwa website merupakan salah satu sarana belajar yang menggunakan jaringan internet dan menyediakan segala bentuk informasi (Dewanto dalam Divayana, Suyasa, \& Sugihartini, 2016) sehingga pembelajaran dapat dilakukan tidak hanya dengan cara tatap muka dan dibatasi oleh waktu (Lim, 2017). Pembelajaran menggunakan website diharapkan menjadi lebih menyenangkan, karena kegiatan tidak hanya berlangsung di dalam kelas, tetapi juga bisa berlangsung dalam kelas kelas virtual, e-learning (Herayanti, Lovy. Fuaddunnazmi \& Habibi, 2017). Pembelajaran berbasis web juga dapat membantu guru dalam mempersiapkan pembelajaran dan sebagai alat penyampaian materi yang sulit. Website dapat digunakan untuk menampilkan berbagai informasi dalam bentuk teks, gambar, video, audio, animasi bergerak atau gabungan kesemuanya yang saling terkait dan dihubungkan dengan jaringan halaman atau yang bisa disebut hyperlink. Sehingga, pembelajaran menjadi lebih menarik dan dapat menambah pengalaman belajar karena dapat memperdalam pemahaman yang lebih baik dari subjek. (Lee \& Owens, dalam Tambunan, 2016).

Media pembelajaran merupakan suatu alat atau perantara yang berguna untuk memudahkan proses belajar mengajar, dalam rangka mengefektifkan komunikasi antara guru dan siswa. Hal ini sangat membantu guru dalam mengajar dan memudahkan siswa menerima dan memahami pelajaran. Proses ini membutuhkan guru yang mampu menyelaraskan antara media pembelajaran dan metode pembelajaran. Pemakaian media pembelajaran dalam proses belajar mengajar juga dapat membangkitkan keinginan dan minat yang baru bagi siswa, membangkitkan motivasi belajar, dan bahkan membawa pengaruh psikologis terhadap siswa. Selain dapat meningkatkan motivasi belajar siswa, pemakaian atau pemanfaatan media juga dapat meningkatkan pemahaman siswa terhadap pelajaran.

Berdasarkan uraian di atas, penelitian ini berinisiatif membuat sebuah prototipe model pembelajaran mata pelajaran bahasa Indonesia berbasis website bagi siswa kelas semester 1 pada jenjang SMA. Pemanfaatan website diharapkan mampu memotivasi guru Bahasa Indonesia untuk meningkatkan efisiensi dan 
efektfitas dalam melaksanakan Pendidikan Jarak Jauh sebagai strategi pembelajaran dalam program Belajar Dari Rumah (BDH). Model pembelajaran Bahasa Indonesia Kelas X semester 1 ini dibuat berbasis Website akan dirancang mengunakan sebuah Course Management System (CMS) yang diharapkan mampu menjadi panduan, ruang belajar dan interaksi bagi guru bahasa Indonesia dan sebuah sarana untuk meningkatkan kompetensi peserta didik dalam masa pandemi.

\section{METODE}

Penelitian Kualitatif terkait cara yang digunakan oleh peneliti dalam mendekati-memahami, menggali, mengungkap fenomena tertentu dari responden penelitiannya. Sejak awal, peneliti harus mampu menentukan metode yang akan digunakan (metode idealnya bersifat tetap, teknik yang bersifat situasional atau fleksibel). Ibarat memancing: ukuran mata kail harus sudah dipilih dari awal terkait jenis/ukuran ikan apa yang mau dipancing atau yang dianggap ada diperairan tsb, tapi umpan yang dapat diganti/tukar. (Mata kail: Metode, umpan: Pendekatan, termasuk didalamnya teknik wawancara dsb). Penelitian Kualitatif digunakan pada penelitian dengan subjek yang tidak dapat terdefinisikan dengan baik. Dapat memahami isu-isu 'sensitif' selama proses penelitian.

Dalam penelitian ini, peneliti menggunakan metode pendekatan penelitian dengan cara Studi Kasus. Dimana kasus penelitian berkonsentrasi kepada Pengembangan Media Pembelajaran Bahasa Indonesia Berbasis Website Jenjang SMA Semester 1 Sebagai Solusi Pembelajaran Jarak Jauh. mengacu pada model FOUR D dan ADDIE untuk menghasilkan sebuah produk media pembelajaran berbasis website.

Pemilihan dua model pendekatan penelitian ini dikarenakan bahwa model penelitian FOUR D lebih mengikat pada perencanaan pembelajaran untuk digunakan dalam situasi pembelajaran di dalam kelas secara aktual, sedangkan pendekatan model ADDIE dipilih dengan alasan desain sistem pembelajaran yang digunakan memperlihatkan tahapan-tahapan dasar desain sistem pembelajaran yang sederhana dan mudah dipelajari, sesuai dengan konsep dalam pengembangan website.

\section{HASIL DAN PEMBAHASAN}

\section{Hasil}

Penelitian ini telah menghasilkan sebuah produk purwarupa (prototype) media pembelajaran Bahasa Indonesia Kelas X semester 1 jenjang SMA melalui tahapan yang mengadaptasi model ADDIE (Branch, 2009). Pemilihan model tersebut dikarenakan model ADDIE sekuensial dan sistematis untuk menghasilkan sebuah produk media pembelajaran. Media pembelajaran Bahasa Indonesia Kelas $\mathrm{X}$ semester 1 jenjang SMA paltform Wordpress dan didukung aplikasi lainnya 
seperti Ms. Office, Adobe photoshop, Google aplication (classroom, drive, gmeet dall), dan Youtube.
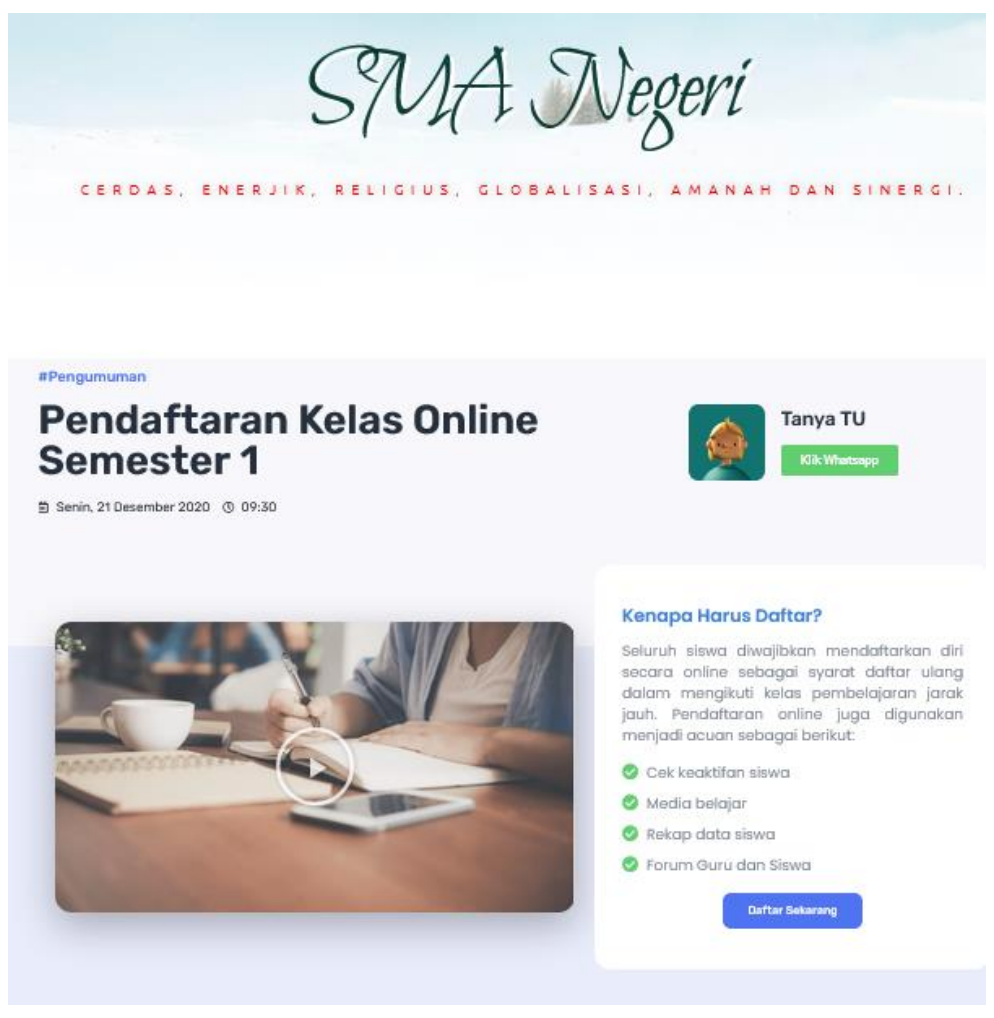

\section{Gambar 1 Tampilan Awal Media Pembelajaran Bahasa Indonesi}

\section{Pembahasan}

Prosedur pengembangan media pembelajaran menulis Bahasa Indonesia Kelas X semester 1 jenjang SMA dimulai dengan tahap kegiatan menganalisis kebutuhan (analysis). Berdasarkan hasil kuesioner analisis kebutuhan siswa, peneliti menyimpulkan bahwa:

1. Guru dan siswa sudah sangat familiar dengan penggunaan Komputer dan perangkat seluler pintar (smartphone) sebagai gadget penunjang aktivitas;

2. Keberadaan website sudah menjadi sebuah kebutuhan dalam kegiatan pembelajaran;

3. Peserta didik mengalami kesulitan dalam proses pembelajaran Bahasa Indonesia Kelas X semester 1 jenjang SMA;

4. Media belajar yang digunakan selama masa pandemi tidak baku sehingga banyak menggunakan aplikasi dan berjalan sendiri; dan

5. Pembelajaran menggunakan media website dirasa lebih menarik dan tidak membosankan. adalah:

Adapun hasil wawancara dengan guru mata pelajaran bahasa Indonesia

1. Guru belum mampu mendesain media pembelajaran yang interakif untuk siswa;

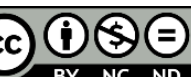


2. Media pembelajaran yang digunakan masih tidak terpusat, diantranya menggunakan google classroom, whatsapp dan zoom, sebagai media yang digunakan dalam pembelajaran. Namun, dalam pelaksanaan pembelajaran, guru dan siswa memiliki kendala karena tidak terpusat dalam satu aplikasi.

Selama ini penyampaian materi Bahasa Indonesia hanya menyuguhkan contoh-contoh tanpa menggunakan media interaktif sehingga kurang tertarik siswa masih kesulitan memahami dan melaksanakan kegiatan belajar. Untuk mengatasi permasalahan tersebut, maka dirasa perlu dibuat media pembelajaran yang dapat menampungsegala kesulitan tersebut agar proses pembelajaran berajalan dengan baik. Melalui pengembangan media pembelajaran ini, diharapkan mampu meningkatkan kualitas dalam pembelajaran pembelajaran Bahasa Indonesia Kelas $\mathrm{X}$ semester 1 jenjang SMA khususnya di SMA Negeri 109 Jakart Selatan.

Tahap berikutnya setelah melakukan analisis kebutuhan yakni tahap rancangan (design). Pada tahap ini peneliti mendesain konsep media pembelajaran berdasarkan hasil analisis kebutuhan melalui pembuatan flowchart, membuat storyboard, menyusun materi, membuat latihan soal, menyusun konten (gambar, video, berita, dan komponen lain berupa ikon-ikon yang akan digunakan dalam media pembelajaran), dan menyusun lembar validasi untuk menilai produk media pembelajaran. Selanjutnya, setelah menyusun rancangan atau desain media pembelajaran adalah tahap pengembangan (develop). Pada tahap ini, peneliti merealisasikan produk media pembelajaran yang berpedoman pada tahap rancangan (design) kemudian mengujicobakan produk media pembelajaran pada tahap implementasi (implementation). Pada tahap uji dilaksanakan melalui dua tahap yang terdiri dari tahap uji coba. Pada tahap uji coba peneliti melibatkan 5 siswa dan 1 orang guru mata pelajaran bahasa Indonesia dengan hasil sebagai berikut:

Tabel 1 Hasil Ujicoba Produk

\begin{tabular}{c|c|ccc}
\hline \multirow{2}{*}{ No. } & \multirow{2}{*}{ Subjek } & \multicolumn{3}{c}{ Aspek } \\
\cline { 3 - 5 } & & Tampilan & Materi & Pembelajaran \\
\hline 1 & Siswa 1 & 5 & 5 & 4 \\
2 & Siswa 2 & 4 & 5 & 4 \\
3 & Siswa 3 & 4 & 5 & 5 \\
4 & Siswa 4 & 4 & 4 & 5 \\
5 & Siswa 5 & 5 & 5 & 5 \\
6 & Guru & 5 & 5 & 5 \\
Total & 27 & 29 & $\mathbf{4 . 6 7}$ \\
\hline \multicolumn{2}{r}{ Rerata } & $\mathbf{4 . 5 0}$ & $\mathbf{4 . 8 3}$ \\
\hline Rerata Keseluruhan & \multicolumn{3}{|c}{ Sangat Layak } \\
\hline
\end{tabular}

Berdasarkan hasil uji coba dengan melibatkan 5 siswa, menunjukan hasil perolehan rerata seccara keseluruhan sebesar 4.6 menunjukan bahwa penilaian 5 orang peserta didik dan satu guru terhadap produk media pembelajaran dengan kategori layak. Kemudian dilanjutkan uji coba pada skala besar media pembelajaran 
mata pelajaran bahasa Indonesia untuk siswa di kelas X SMA Negeri 109 Jakarta Selatan, menunjukkan hasil perolehan sebagai berikut:

Skor rerata secara keseluruhan sebesar 4,6. Skor rerata keseluruhan tersebut dikonversi ke dalam penskoran skala lima terletak pada rentang $X>4,20$ yang menunjukkan bahwa penilaian peserta didik terhadap produk media pembelajaran dengan kategori layak. Menunjukan bahwa Pengembangan Media Pembelajaran Bahasa Indonesia Berbasis Website layak menjadi media belajar pada masa pandemi dengan metode Pembelajaran Jarak Jauh yang tidak membosankan serta dapat memotivasi siswa dalam kegiatan belajar.

\section{SIMPULAN}

Berdasarkan hasil penelitian yang telah dilaksanakan diperoleh simpulan bahwa hasil penelitian dan pembuatan media pembelajaran berbasi website mata pelajaran Bahasa Indonesia kelas $X$ semester 1 jenjang SMA telah diciptakan. Media pembelajaran yang dikembangkan memuat materi Teks Laporan Observasi, Eksosisi, Anekdot, dan Cerita Rakyat. Media pembelajaran yang dibuat mengacu pada silabus dan RPP yang sudah dibuat berdasarkan observasi dan rujukan pembelajaran tatap muka terdahulu yang memenuhi unsur KI dan KD, Materi, Evaluasi, Pustaka, Petunjuk, dan Profil. Pembuatan media pembelajaran Bahasa Indonesia kelas $X$ semester 1 jenjang SMA memeiliki fitur dimana guru mampu mengunggah materi, kuis dan penilaian dan siswa memiliki fitu untuk mengakses semua informasi yang diunggah. Media pembelajaran ini juga memfasilitasi fitur evaluasi formatif pada menu evaluasi. Media pembuatan media pembelajaran Bahasa Indonesia kelas X semester 1 jenjang SMA Model ADDIE dan dengan rujukan model FUOR D sebagai penyeimbangnya dan dibuat menggunakan open sourse course management system (CMS) berupa WordPress, Webhosting (digunakan mulai dari penyimpanan serta aplikasi website, file transfer pada FTP, pusat data email dan lain sebagainya), Plugin (elementor). Pembuatan media pembelajaran Bahasa Indonesia kelas X semester 1 jenjang SMA ini telah layak digunakan. Hal tersebut terbukti dari hasil kelayakan penilaian peserta didik terhadap media pembelajaran pembuatan media pembelajaran Bahasa Indonesia kelas X semester 1 jenjang SMA. Hasil uji coba oleh peserta didik dengan kategori layak. Hal tersebut terbukti dari hasil rekapitulasi penilaian dari segi kualitas tampilan media, materi pada media, dan pembelajaran memeroleh skor rerata sebesar 4.6. Skor rerata hasil penilaian peserta didik tersebut masuk kategori layak.

\section{DAFTAR PUSTAKA}

Branch, R. M. (2009). Instructional design: The ADDIE approach (Vol. 722). Springer Science \& Business Media.

Divayana, D. G. H., Suyasa, P. W. A., \& Sugihartini, N. (2016). Pengembangan media pembelajaran berbasis web untuk matakuliah kurikulum dan 
pengajaran di jurusan pendidikan teknik informatika Universitas Pendidikan Ganesha. Jurnal Nasional Pendidikan Teknik Informatika: JANAPATI, 5(3), 149-157.

Herayanti, L., Fuaddunnazmi, M., \& Habibi, H. (2017). Pengembangan media pembelajaran berbasis moodle pada mata kuliah fisika dasar. Jurnal Pendidikan Fisika dan Teknologi, 1(3), 205-209.

Lim, S. H. (2017). Hubungan kepimpinan instruksional, budaya organisasi dan organisasi pembelajaran di sekolah berprestasi tinggi di Malaysia (Doctoral dissertation, Universiti Pendidikan Sultan Idris).

Rusman. (2012). Belajar dan pembelajaran berbasis komputer. Bandung: Alfabeta.

Rusman. (2017). Belajar dan pembelajaran. In Belajar dan Pembelajaran Berorientasi Standar Proses Pendidikan (pp. 75-132). Jakarta: KENCANA

Tambunan, N. (2016). Pengaruh strategi pembelajaran dan minat belajar terhadap kemampuan berpikir kreatif matematis siswa. Formatif: Jurnal Ilmiah Pendidikan MIPA, 6(3). 